\title{
Evolution of $V R N-1$ homoeologous loci in allopolyploids of Triticum and their diploid precursors
}

\author{
Andrey B. Shcherban ${ }^{*}$ and Elena A. Salina \\ From 4th International Scientific Conference "Plant Genetics, Genomics, Bioinformatics and Biotechnology" (PlantGen 2017) \\ Almaty, Kazakhstan. 29 May - 2 June 2017
}

\begin{abstract}
Background: The key gene in genetic system controlling the duration of the vegetative period in cereals is the VRN1 gene, whose product under the influence of low temperature (vernalization) promotes the transition of the apical meristem cells into a competent state for the development of generative tissues of spike. As early genetic studies shown, the dominant alleles of this gene underlie the spring forms of plants that do not require vernalization for this transition. In wheat allopolyploids various combinations of alleles of the VRN1 homoeologous loci (VRN1 homoeoalleles) provide diversity in such important traits as the time to heading, height of plants and yield. Due to genetical mapping of VRN1 loci it became possible to isolate the dominant VRN1 alleles and to study their molecular structure compared with the recessive alleles defining the winter type of plants. Of special interest is the process of divergence of VRN1 loci in the course of evolution from diploid ancestors to wheat allopolyploids of different levels of ploidy.

Results: Molecular analysis of VRN1 loci allowed to establish that various dominant alleles of these loci appeared as a result of mutations in two main regulatory regions: the promoter and the first intron. In the diploid ancestors of wheat, especially, in those of A- genome (T. boeoticum, T. urartu), the dominant VRN1 alleles are rare in accordance with a limited distribution of spring forms in these species. In the first allotetraploid wheat species including T. dicoccoides, T. araraticum (T. timopheevii), the spring forms were associated with a new dominant alleles, mainly, within the VRN-A1 locus. The process of accumulation of new dominant alleles at all VRN1 loci was significantly accelerated in cultivated wheat species, especially in common, hexaploid wheat T. aestivum, as a result of artificial selection of spring forms adapted to different climatic conditions and containing various combinations of VRN1 homoeoalleles.
\end{abstract}

Conclusions: This mini-review summarizes data on the molecular structure and distribution of various VRN1 homoeoalleles in wheat allopolyploids and their diploid predecessors.

Keywords: Wheat, Vernalization, VRN1 gene, Homoeoalleles, Allopolyploids, Promoter, First intron

\section{Background}

Transition of plant from the vegetative stage to the generative one represents one of the most critical stages in the life cycle of a plant, since on its proper course depends: whether the plant gives the offspring. An active study of genetic mechanisms of transition to the stage of flowering on model plant species has made it possible to

\footnotetext{
*Correspondence: atos@bionet.nsc.ru

The Federal Research Center "Institute of Cytology and Genetics of Siberian Branch of the Russian Academy of Sciences", Lavrentiev ave. 10, Novosibirsk 630090, Russia
}

(c) The Author(s). 2017 Open Access This article is distributed under the terms of the Creative Commons Attribution 4.0 International License (http://creativecommons.org/licenses/by/4.0/), which permits unrestricted use, distribution, and reproduction in any medium, provided you give appropriate credit to the original author(s) and the source, provide a link to the Creative Commons license, and indicate if changes were made. The Creative Commons Public Domain Dedication waiver (http://creativecommons.org/publicdomain/zero/1.0/) applies to the data made available in this article, unless otherwise stated. transition, depending on internal and external factors, such as temperature, length of daylight, hormone concentration, et cetera. The key genes of this system were identified and functionally characterized in the basic model object of plants, Arabidopsis thaliana (Reviewed in [1]). These genes can be divided into three types: 1) genes of regulatory cascades; 2) genes- integrators; 3) genes of the flowering meristems identity. Genes of the first type are conductors that transmit signals from separate external or internal factors to genes- integrators. 
The latter combine various regulatory cascades and, under a certain combination of factors, directly activate genes that induce the formation of flowering meristems.

In cereal plants, the duration of the vegetative period is determined by the interconnected systems of genes of vernalization response (VRN1, VRN2), response to photoperiod (PHYC, PHYB, PPD1, CO1, CO2), which trigger the genes of flowering meristems: VRN1 and LFY2 through the gene- integrator FT1 (Reviewed in $[2,3]$ ). FT1 is a homolog of Arabidopsis FT, which encodes a mobile protein critical for the transmission of day-length signals from leaves to the shoot apical meristem [4]. A special role in this system is assigned to the VRN1 gene, which combines the functions of a response to the vernalization signal and induction of the formation of flowering meristems from the apical cells of sprout. This gene encodes a MADS- domain containing transcription factor homologous to the product of the AP1 gene of Arabidopsis [5]. Prolonged exposure to low temperatures (vernalization) induces the transcription of VRN1 in both leaves and at the shoot apex [6, 7]. In the apex, VRN1 initiates the transition of the shoot apical meristem to the reproductive stage whereas, in the leaves, it upregulates FT1 directly [8], or through the VRN2 gene [9]. Initially, deletion of the VRN1 gene was thought to be the cause of irreversible loss of reproductive capacity in a radiation mutant in diploid wheat (Triticum monococcum L.), designated maintained vegetative phase (mvp) $[6,10]$. However, a recent studies establish that, besides $V R N 1$, some other genes, like $P H Y C, V R N-A m 1$, may be essential for wheat flowering raising the possibility that their deletion is responsible for the nonflowering phenotype of the $m v p$ mutant $[3,11]$. It should be noted that in allopolyploid cereals, including common hexaploid wheat $T$. aestivum L. $(2 \mathrm{n}=42$; BBAADD), the genetic mode of the flowering regulation is greatly complicated due to the presence of homoeologous copies of each gene.

In common wheat the homoeologous loci VRN-A1, $V R N-B 1$ and $V R N-D 1$ were mapped on chromosomes of group 5 [12-14]. All three homoeologs are functional and their combination provides a predominant part of biodiversity of winter and spring forms of this species [15]. Winter wheat contains recessive alleles at each of these loci, while spring wheat, in at least one of them, has a dominant allele. The dominant allele VRN-A1 causes complete insensitivity to vernalization and is epistatic with respect to the dominant $V R N-B 1$ and $V R N-D 1$ alleles, which cause little sensitivity to vernalization [16]. A wide range of the heading time in spring wheat is provided by various combinations of dominant alleles of the homoeologous VRN1 loci that also influence the height of plants and yield [17-19]. The earliest in the time of heading are genotypes with three dominant alleles, however, they tend to be low- yielding. Genotypes with two dominant alleles (VRN-A1/ $V R N-B 1$ or $V R N-D 1)$ ripen somewhat later and have higher yields. The presence of only one of the weak alleles $V R N-B 1$ or $V R N-D 1$ provides the latest ripening of spring varieties $[16,20]$. The purpose of this mini-review is to analyze the available molecular genetical data on the formation of the VRN1 allelic system at the following stages of wheat evolution: 1) in diploid donor species of A, B, G, and D genomes; 2) in tetraploid species (BBAA and GGAA genomes); 3) in hexaploid wheat (BBAADD).

\section{The main regulatory regions of VRN1 loci affecting their expression}

The molecular analysis of various VRN1 homoeoalleles was first carried out, mainly, on polyploid wheat species as an object. It was shown that the dominant alleles of these loci are, mainly, associated with mutations in two basic regulatory regions: the promoter and the first (1st) intron $[21,22]$. It is assumed that mutations in these regions disrupt interaction with regulatory factors leading to independent of ambient temperature, constitutive expression of VRN1 in spring forms [2]. The dominant $V R N-A 1$ alleles associated with insertions $(V R N-A 1 a)$ or deletions (VRN-A1b,VRN-A1d, VRN-A1e) in the promoter have been identified (Table 1). Initially, mutations in the CArG-like motif located $170 \mathrm{bp}$ upstream from the starting ATG- codon were considered as the main determinants of the spring type [5]. However, later this motif was found to be invariant in a number of spring genotypes [23, 24]. Moreover, the complete deletion of the CArG-box retained sensitivity to vernalization. It was assumed that the CArG box can participate in response to photoperiod by binding a repressor protein expressed on a short day [25].

The so-called VRN box ("TTAAAAACCCCTCCCC"), directly 5 '-adjacent to the CArG box [24], seems to have the greatest impact on the sensitivity to vernalization. Namely this motif is affected by insertions and deletions in the dominant alleles VRN-A1a, VRN-A1d, VRN-A1e, strictly associated with the spring type of growth [21, 26-28]. Recently, it has been established that even point mutations in the VRN box (the alleles Vrn-A1b.3, Vrn-A1b.4 and Vrn-A1i) are sufficient for transformation into the spring type and the combination of these mutations can modulate the response to vernalization [29]. Upstream of the VRN box are binding sites for bZIP transcription factors (ACGT sites) [30, 31]. These sites can bind the TaFDL2 protein, which forms a complex with the product of the VRN3 gene-integrator. It is this interaction that is supposed to provide the inducing effect of the $V R N 3$ gene on the transcription of VRN1 [32].

Besides the VRN1 promoter region, the region of the 1st intron also began to be considered as an important determinant of the spring habit after the discovery in 


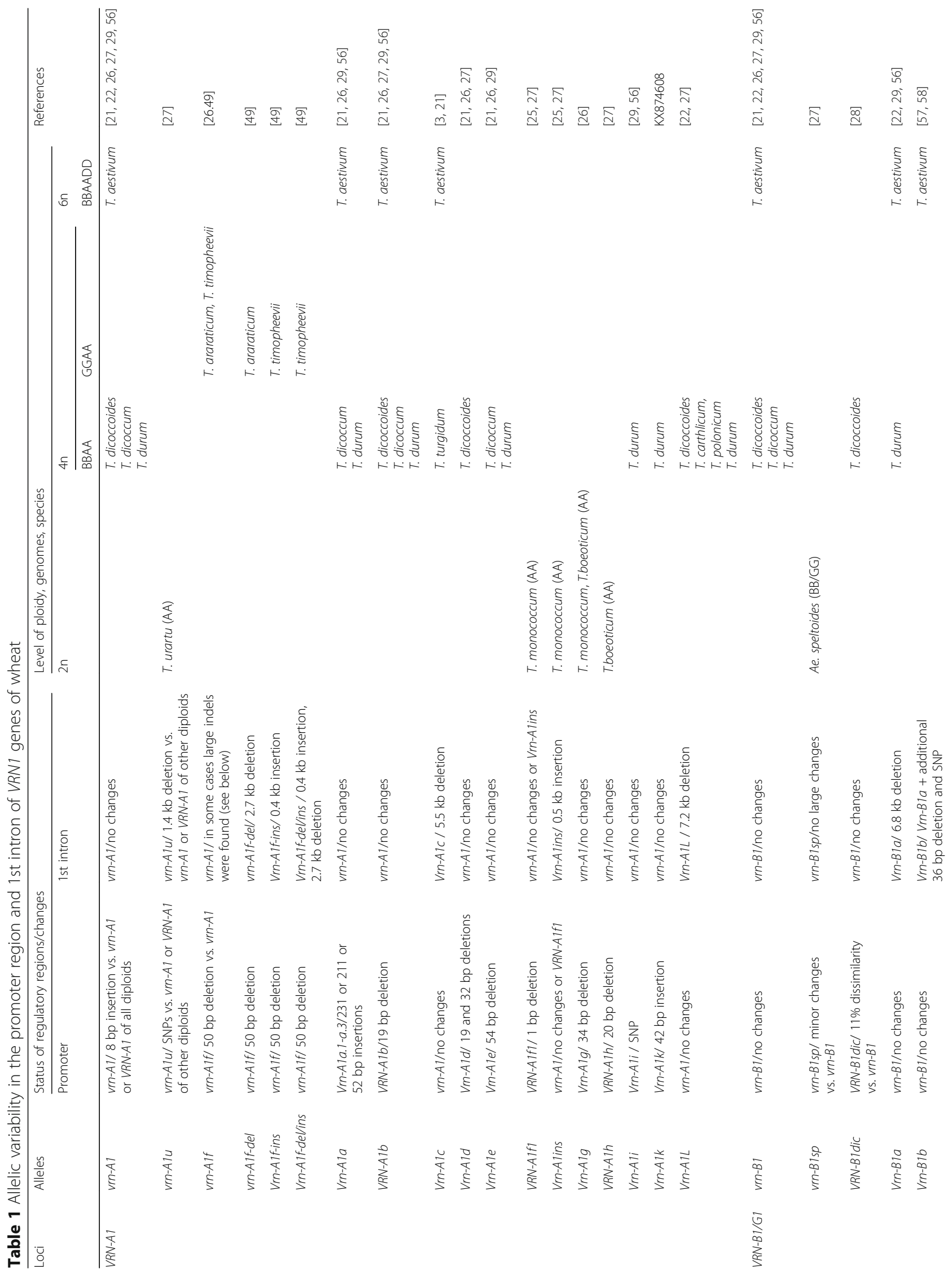




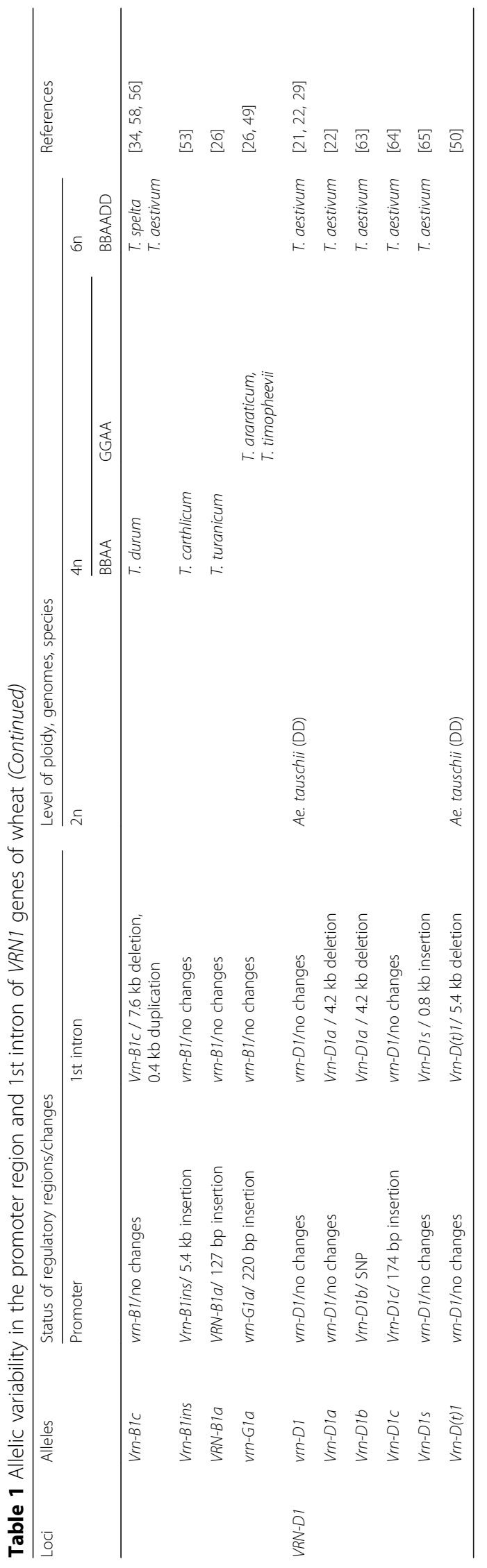


wheat and barley of a number of dominant alleles containing only deletions in the 1st intron (the critical region is within $2.8 \mathrm{~kb}$ from the beginning of this intron) $[22,33,34]$. For example, the dominant alleles $V R N-A 1 c$, $V R N-B 1 a$ and $V R N-D 1 a$, widely distributed in common wheat, contain large deletions in intron 1 , whereas their promoter regions do not differ from those in the corresponding recessive alleles of these loci (Table 1). It was found that the repressed state of the VRN1 gene observed in winter forms prior to vernalization is associated with a high level of methylation of histone H3 in the flanking region of the 1st intron and the degree of methylation is significantly reduced by deletions overlapping this critical region [35, 36]. An epigenetic model of the VRN1 gene regulation was proposed, in which the $5^{\prime}$-flanking region of the 1st intron is attributed to the binding of chromatin modification factors affecting the transcription level of VRN1 [37, 38]. According to the post-transcriptional model of regulation, this region contains a binding site for the Glycine-rich RNA-binding protein 2 (TaGRP2), which inhibits VRN1 expression by binding with the VRN1 premRNA [39, 40].

An assessment of the relative level of transcription of various homoeoalleles VRN1 was carried out using three near-isogenic lines Triple Dirk of $T$. aestivum bearing the dominant alleles VRN-A1,VRN-B1 and VRN-D1 [41]. An established higher level of transcription of $V R N-A 1$, compared to two other homoeoalleles, leads to an earlier heading of the corresponding line. This may be due to the existence of several paralogs of this gene $[42,43]$ which may provide its overexpression, explaining the epistatic effect of VRN-A1 in the digenic dominant VRN1 genotypes (see above). It should be noted that differences in the level of transcription and phenotypic effect between dominant alleles of one homoeologous locus can be comparable with those between alleles of different loci. This was shown by Shcherban et al. [38] using near-isogenic lines containing $V R N-B 1 a$ and $V R N-B 1 c$ alleles. The revealed level of transcription of $V R N-B 1 c$ was 10 times higher, probably, due to large structural changes (deletion and duplication) in the 1st intron compared with the first allele.

\section{The VRN1 gene- associated prerequisites of spring growth} habit in diploid precursors of wheat

Most of the wild Triticeae species both diploid and polyploid have a winter growth habit, suggesting that the recessive VRN1 allele is the ancestral, original form [44]. Spring growth habit determined by dominant VRN1 alleles could result from selection of mutations appearing during the adaptation of plants to environments that differ from the original. Some authors suggest that the spring type might have evolved from a previous winter plant prototype as an adaptation to warmer conditions, the feature that might be characteristic of both diploid and polyploid species $[45,46]$. In support of this idea, Kato et al. [47] found that the distribution of spring forms of wild species $T$. dicoccoides Thell $(2 \mathrm{n}=28$; BBAA) is sporadic and restricted to areas where vernalization is not required. Differentiation into spring and winter types was revealed in all Triticum and Aegilops diploid $(2 \mathrm{n}=14)$ species with the frequency of spring forms varying from $2 \%$ (T. urartu) up to $100 \%$ (T. sinskajae) [44].

In diploid species related to the A-genome (T. boeoticum Boiss., T. monococcum L., T. urartu Tum. ex Gandil.), the dominant VRN1 alleles were most common among accessions of einkorn wheat T. monococcum, one of the earliest cultivated forms of wheat [48]. Shcherban et al. [27] revealed Vrn-A1ins allele (Table 1) in 35\% of the studied accessions of T. monococcum and a total frequency of all dominant alleles was close to the percentage of spring forms (47\%), established earlier for this species [44]. In the wild progenitor of $T$. monococcum - T. boeoticum, a few spring forms were associated with the VRN-Alh allele, although it was also found in some winter accessions (an optional type) [27]. The dominant $V R N-A 1 g$ allele was quite rare in both T. monococcum and T. boeoticum [26]. The structure of regulatory regions of VRN1 was highly conserved in the predominantly winter species, $T$. urartu, a donor of A-genome to polyploids. Interestingly, the latter species, in comparison with the other two diploids, has different mutations in both the promoter (nucleotide substitutions) and 1st intron (deletion of $1.4 \mathrm{~kb}$ ) of VRN1 providing specific identification of T. urartu and the corresponding A-genome in polyploids. However, all these mutations displayed no influence on vernalization requirements in all studied accessions, therefore the common VRN1 allele of T. urartu is recessive (vrn-A1u; Table 1).

In Ae. speltoides Tausch, the presumable donor of $\mathrm{B}$ and G-genomes to polyploids, the structure of the promoter of $V R N-1$ was more polymorphic compared to the Triticum A-genome species, however, most of this variation was upstream from the conserved region encompassing about $0.3 \mathrm{~kb}$ from the start codon and containing the putative regulatory sites [49]. No large indels were revealed in the $V R N-1$ 1st intron of $A e$. speltoides. All the studied accessions of this species were of winter type (allele vrn-B1sp; Table 1). Untill now, the dominant VRN1 alleles associated with spring growth have not been found in Ae. speltoides.

The only dominant allele $V R N-D(t) 1$ was found in 9 out of 211 accessions of Ae. tauschii Coss., the proposed donor of D-genome to common wheat [50]. This allele contains deletion of a 5.4-kb sequence in the critical region of the VRN1 1st intron (see above) and was strongly associated with a lack of vernalization requirement (Table 1).

Thus, the dominant VRN1 alleles within diploid species, presumable donors of $\mathrm{A}, \mathrm{B}(\mathrm{G})$ and $\mathrm{D}$-genomes, 
have a rare occurrence as compared with polyploid species (see below) that is consistent with the predominant winter type of these species. The only exception is $T$. monococcum, in which the spread of the dominant VRN1 alleles and corresponding spring forms could occur due to the selection process carried out by human. This process resulted to a wide distribution of einkorn wheat from the Fertile Crescent to the more northern regions including the Caucasus, the Balkans, and central Europe [51].

\section{Polymorphism of VRN1 loci in tetraploid wheat species of different origin}

An important issue is the origin of the VRN1 alleles associated with spring growth habit in the first tetraploid wheat species of two independent evolutionary lines: the Emmer line (BBAA) and the Timopheevii line (GGAA). The first line begins with the wild tetraploid $T$. dicoccoides, from which all the main cultural allopolyploids, including hard $T$. durum Desf. (BBAA) and common hexaploid wheat originated. The second line includes the wild species $T$. araraticum Jakubz. and derived from it, domesticated spring form- T. timopheevii (Zhuk) Zhuk.

Comparison of the VRN1 alleles set of in the first tetraploid wheat species and those in the diploids shows that in the first tetraploids, the emergence of spring forms was associated with the appearance of new dominant VRN1 alleles that are not related in origin to the dominant alleles of diploid predecessors (Table 1). The set of alleles of $T$. dicoccoides differs from that of Timopheevii tetraploids indicating an independent origin of the spring type of growth within these two branches of allopolyploids. In spring wheat, $T$. timopheevii, this trait is apparently associated with the insertion of a miniature transposon (MITE) in the 1st intron of the VRN-A1 locus (alleles Vrn-A1f-del/ins and Vrn-A1f-ins; Table 1) $[49,52]$. In $T$. dicoccoides, spring forms were associated with changes in the VRN-A1 promoter: deletions of variable size (Vrn-A1b, Vrn-A1d and Vrn-Ale alleles), nucleotide substitution (Vrn-Ali) and a large deletion in the 1st intron $(V r n-A 1 L)$ [26-29]. Besides, after the divergence of both lines of tetraploids some changes in the VRN-A1 promoter appeared to be not associated with spring growth habit including a 8 bp insertion in all Emmer wheats and a 50 bp deletion in Timopheevii wheats [49].

In contrast to VRN-A1, the VRN-B1 locus in 83 accessions of $T$. dicoccoides displayed no significant indels, affecting the main regulatory sites and associated with the spring type [27]. The VRN-B1dic allele with a number of minor mutations within the promoter (SNPs, deletions up to $7 \mathrm{bp}$ ) was detected in one spring accession of $T$. dicoccoides, however, its influence on vernalization response has not been established definitely (Table 1).
In one accession of the Turanian wheat T. turanicum Jakubz. (BBAA) allele VRN-B1a (does not correspond to the dominant Vrn-B1a; Table 1) with an insertion in the $V R N-B 1$ promoter was found [26]. Interestingly, this insertion is homologous to the insertion in the VRN-A1a allele, however, it has other location- at position -100 from the start codon. The insertion of a retrotransposon of $5.4 \mathrm{~kb}$ in the $V R N-B 1$ promoter was detected in tetraploid Persian wheat $T$. carthlicum Nevski, and, unlike the previous case, its association with the spring forms was confirmed [53].

Besides $T$. dicoccoides, the Vrn-A1L allele containing large deletion in the 1st intron was identified in other Emmer tetraploid species of a later origin: T. carthlicum, T. polonicum L., $T$. durum $[29,54]$. In $T$. durum the dominant $V R N-B 1 a$ and $V R N-B 1 c$ alleles appeared, having deletions of 6.8 and $7.6 \mathrm{~kb}$, respectively, in the 1st intron (Table 1). The latter allele seems to have originated from $V R N-B 1 a$ due to an additional deletion of $0.8 \mathrm{~kb}$ and a duplication of $0.4 \mathrm{~kb}[38,55]$. The both $V R N-B 1$ alleles are higly distributed among spring varieties of common wheat (see below).

The only identified mutation affecting VRN-G1 locus in Timopheevii wheats is an insertion of foldback element in the promoter region at position -99 from the ATG-codon (allele VRN-G1a) [26]. However, in fact this allele is recessive since it was later found in winter accessions of $T$. araraticum [49].

Thus, in the first allotetraploid wheat species of both Emmer and Timopheevii lines the most variability affected the locus $V R N-A 1$, while the other homoeolog$V R N-B 1$ (G1) remained unchanged in spring forms ( $T$. dicoccoides), or mutation in it did not result to the spring phenotype (Timopheevii, allele VRN-G1a). On a later stages of evolution of Emmer allotetraploids, especially, in the cultivated T. durum, different $V R N-B 1$ alleles appeared containing mutations in the promoter or 1 st intron regions.

\section{Variability of VRN1 loci in hexaploid wheat}

Many known VRN1 alleles, common in hexaploid wheat, originated at the tetraploid stage. This refers to such alleles as VRN-A1a, VRN-A1b,VRN-A1c,VRN-B1a, $V R N-B 1 c$ [21, 22, 26, 29, 55-58]. The most ubiquitous among them are the VRN-A1a allele with a foldback insertion in the VRN-box and the VRN-B1a allele. Simultaneously, a number of a new alleles including $V R N-B 1$ $(V R N-B 1 b)$ and, especially, VRN-D1 (VRN-D1a, VRN-D1b, $V R N-D 1 c, V R N-D 1 s)$ loci appeared in hexaploid wheat (Table 1).

The $V R N-B 1 b$ allele appears to have originated from the $V R N-B 1 a$ allele, since along with large deletion in the 1st intron, characteristic of the latter, it has an additional SNP and a 36 bp deletion [57]. This allele has 
been detected in common wheat originating from North America and was associated with the spring growth habit [58].

The dominant $V R N-D 1 a$ allele was first isolated from spring near-isogenic line TDE (Table 1). As shown, $V R N-D 1 a$ is the predominant allele in spring wheat genotypes adapted to tropical and subtropical regions [59-62]. The $V R N-D 1 b$ allele has been originated from the previous allele due to SNP in the CArG-box at the promoter region [63]. Since the F2 population plants with $V R N-D 1 b$ headed 32 days later than those with $V R N-D 1 a$, the authors suggest that a single nucleotide mutation at promoter region may modify the basal activity level of an allele of VRN1 that is already active (due to the loss of segment in intron 1). The VRN-D1c allele with 174-bp insertion in the promoter region was discovered in three out of 205 Chinese wheat cultivars [64]. As suggested, the insertion in Vrn-D1c may contribute to the increase in gene expression and cause early heading and flowering due to transcriptional cis-elements. In the same year Muterko et al. [65] found the VRN-D1s allele resulted from DNA transposon insertion of $844 \mathrm{bp}$ in the 1st intron and associated with spring form (Table 1).

It can be assumed that the wide distribution of spring forms and associated with them combinations of VRN1 homoeoalleles in common wheat is largely due to artificial selection directed to adaptation of wheat to different climatic conditions. As one of the illustrations, the analysis of distribution of different VRN1 haplotypes among varieties of spring common wheat from different ecogeographical regions of Europe and Russia can be presented [34, 59]. For the group of cultivars of the northern and central Europe and the most of territory of Russia, the digenic dominant haplotypes at the VRN-A1 and $V R N-B 1$ loci are characteristic, while for the southern European group of cultivars, the monogenic dominant haplotypes containing either the dominant $V R N-B 1$ or $V R N-D 1$ are mostly widespread. The latter group of cultivars had a later date of heading compared to the cultivars of the first group. Therefore, the monogenic $V R N-B 1 / V R N-D 1$ haplotypes could have a breeding advantage in the subtropical southern regions, providing a longer vegetative period that is most effective for this zone in terms of yield. The early ripening, digenic dominant haplotypes, in turn, have an advantage in regions with a temperate climate, where there is a risk of early fall frosts [59].

\section{Conclusions}

In the diploid predecessors of polyploid wheats, the dominant VRN1 alleles associated with spring forms have a limited distribution, mainly, in a specific climatic regions where such forms may receive a natural selective advantage over winter forms. The origin of spring forms in polyploids, starting from the first wild-growing tetraploid species (BBAA/GGAA) is due to emergence and spread of a new dominant $V R N-1$ alleles, not related by origin to alleles of the diploid species, presumed donors of A-, B (G) and D- subgenomes. In cultivated wheat polyploids, especially in common wheat, the process of artificial selection significantly enhance the spread of different VRN1 alleles at each of the homoeologous loci and their combinations that determine the optimal heading time for a district geographical regions.

\section{Acknowledgements \\ We are grateful to Carly Schramm for comments and English polishing in the manuscript. \\ Funding \\ This study and publication costs is supported by the Russian Scientific Foundation (http://rscf.ru/) grant № 14-14-00161.}

\section{Availability of data and materials}

All data analyzed in this review were obtained in the previously published articles (see references).

\section{About this supplement}

This article has been published as part of BMC Plant Biology Volume 17 Supplement 1, 2017: Selected articles from PlantGen 2017. The full contents of the supplement are available online at https:/bmcplantbiol.biomedcentral.com/ articles/supplements/volume-17-supplement-1.

\section{Authors' contributions}

Conceptualization: ABS, EAS. Writing - original draft preparation: ABS. Writing - review and editing: ABS, EAS. Both authors read and approved the final manuscript.

Ethics approval and consent to participate

Not applicable.

\section{Consent for publication}

Not applicable.

\section{Competing interests}

The authors declare that they have no competing interests.

\section{Publisher's Note}

Springer Nature remains neutral with regard to jurisdictional claims in published maps and institutional affiliations.

Published: 14 November 2017

References

1. Jung C, Müller AE. Flowering time control and applications in plant breeding. Trends Plant Sci. 2009;14:563-73.

2. Distelfeld A, Li C, Dubcovsky J. Regulation of flowering in temperate cereals. Curr Opin Plant Biol. 2009:12:1-7.

3. Chen $A, L i C, H u$ W, Lau MY, et al. PHYTOCHROME C plays a major role in the acceleration of wheat flowering under long-day photoperiod. Proc Natl Acad Sci U S A. 2014;111(28):10037-44.

4. Corbesier L, Vincent C, Jang S, Fornara F, Fan Q, et al. FT protein movement contributes to long-distance signaling in floral induction of Arabidopsis. Science. 2007;316(5827):1030-3.

5. Yan L, Loukoianov A, Tranquilli G, Helguera M, et al. Positional cloning of the wheat vernalization gene VRN1. Proc Natl Acad Sci U S A. 2003;100:6263-8.

6. Murai K, Miyamae M, Kato H, Takumi S, Ogihara Y. WAP1, a wheat APETALA1 homolog, plays a central role in the phase transition from vegetative to reproductive growth. Plant Cell Physiol. 2003;44:1255-65.

7. Sasani S, Hemming MN, Oliver SN, Greenup A, Afshari RT, et al. The influence of vernalization and daylength on expression of flowering-time 
genes in the shoot apex and leaves of barley (Hordeum vulgare). J Exp Bot. 2009;60:2169-78

8. Deng W, Casao MC, Wang P, Sato K, Hayes PM, et al. Direct links between the vernalization response and other key traits of cereal crops. Nat Commun. 2015;6:5882.

9. Chen A, Dubcovsky J. Wheat TILLING mutants show that the vernalization gene VRN1 down-regulates the flowering repressor VRN2 in leaves but is not essential for flowering. PLoS Genet. 8(12):e1003134.

10. Shitsukawa N, Ikari C, Shimada S, Kitagawa S, et al. The einkorn wheat (Triticum monococcum) mutant, maintained vegetative phase, is caused by a deletion in the VRN-1 gene. Genes Genet Syst. 2007;82:167-70.

11. Distelfeld A, Dubcovsky J. Characterization of the maintained vegetative phase deletions from diploid wheat and their effect on VRN2 and FT transcript levels. Mol Gen Genomics. 2010;283(3):223-32.

12. Law CN, Worland AJ, Giorgi B. The genetic control of ear-emergence time by chromosomes $5 A$ and $5 D$ of wheat. Heredity. 1975;36:49-584.

13. Galiba G, Quarrie SA, Sutka J, Morgounov A, Snape JW. RFLP mapping of the vernalization (Vrn 1) and frost resistance (Fr1) genes on chromosome 5A of wheat. Theor Appl Genet. 1995;90:1174-9.

14. Dubcovsky J, Lijavetzky D, Appendino L, Tranquilli G. Comparative RFLP mapping of Triticum monococcum genes controlling vernalization requirement. Theor Appl Genet. 1998;97:968-75.

15. McIntosh RA, Hart GE, Devos KM, Gale MD, Rogers WJ. Catalogue of gene symbols for wheat. Proceed 9th Intern Wheat Genet Symp, Saskatoon, Canada. 1998:5:1-235.

16. Pugsley AT. A genetic analysis of spring-winter habit of growth in wheat. Aust J Agric Res. 1971;22:21-31.

17. Goncharov NP. Genetic resources of wheat related species:the Vrn genes controlling growth habit (spring vs. winter). Euphytica. 1998;100:371-6

18. Stelmakh AF. Genetic effects of Vrn genes on heading date and agronomic traits in bread wheat. Euphytica. 1993;65:53-60.

19. Stelmakh AF. Genetic systems regulating flowering response in wheat. Euphytica. 1998;100:359-69.

20. Košner J, Pánková K. Chromosome substitutions with dominant loci Vrn-1 and their effect on developmental stages of wheat. Czech J Genet Plant Breed. 2004;40(2):37-44.

21. Yan L, Helguera M, Kato K, Fukuyama S, Sherman J, Dubcovsky J. Allelic variation at the VRN-1 promoter in polyploid wheat. Theor Appl Genet. 2004;109:1677-86.

22. Fu D, Szucs P, Yan L, Helguera M, et al. Large deletions within the first intron in VRN-1 are associated with spring growth habit in barley and wheat. Mol Gen Genomics. 2005;273:54-65.

23. von Zitzewitz J, Szucs P, Dubcovsky J, Yan L, et al. Molecular and structural characterization of barley vernalization genes. Plant Mol Biol. 2005;59:449-67.

24. Pidal B, Yan L, Fu D, Zhang F, Tranquilli G, Dubcovsky J. The CArG-box located upstream from the transcription start of wheat vernalization gene VRN-1 is not necessary for the vernalization response. J Heredity. 2009;100:355-64

25. Dubcovsky J, Loukoianov A, Fu D, Valarik M, et al. Effect of photoperiod on the regulation of wheat vernalization genes V rn-1 and V rn-2. Plant Mol Biol. 2006;60:469-80.

26. Golovnina KA, Kondratenko E, Blinov AG, Goncharov NP. Molecular characterization of vernalization loci VRN1 in wild and cultivated wheats. BMC Plant Biol. 2010;10:168.

27. Shcherban $A B$, Strygina KV, Salina EA. VRN-1 gene- associated prerequisites of spring growth habit in wild tetraploid wheat $T$. dicoccoides and the diploid a genome species. BMC Plant Biol. 2015;15:94.

28. Konopatskaia I, Vavilova V, Kondratenko E, Blinov A, Goncharov NP. VRN genes variability in tetraploid wheat species with a spring growth habit. BMC Plant Biol. 2016;16(Suppl 3):244.

29. Muterko A, Kalendar R, Salina E. Novel alleles of the VERNALIZATION1 genes in wheat are associated with modulation of DNA curvature and flexibility in the promoter region. BMC Plant Biol. 2016;16(S1):65-81.

30. Foster R, Izawa T, Chua NH. Plant bZIP proteins gather at ACGT elements. FASEB J. 1994;8(2):192-200

31. Martinez-Garcia JF, Moyano E, Alcocer MJC, Martin C. Two bZIP proteins from Antirrhinum flowers preferentially bind a hybrid C-box/G-box motif and help to define a new subfamily of bZIP transcription factors. Plant J. 1998;13(4):489-505.

32. Li C, Dubcovsky J. Wheat FT protein regulates VRN1 transcription through interactions with FDL2. Plant J. 2008;55(4):543-54.
33. Szücs P, Skinner JS, Karsai I, Cuesta-Marcos A, et al. Validation of the VRN-H2/ $V R N-H 1$ epistatic model in barley reveals that intron length variation in VRN-H1 may account for a continuum of vernalization sensitivity. Mol Genet Genomics. 2007:277:249-61.

34. Shcherban AB, Efremova TT, Salina EA. Identification of a new Vrn-B1 allele using two near-isogenic wheat lines with difference in heading time. Mol Breed. 2012;29(3):675-85

35. Oliver SN, Finnegan EJ, Dennis ES, Peacock WJ, Trevaskis B. Vernalizationinduced flowering in cereals is associated with changes in histone methylation at the VERNALIZATION1 gene. Proc Natl Acad Sci U S A. 2009;106:8386-91.

36. Oliver SN, Deng W, Casao MC, Trevaskis B. Low temperatures induce rapid changes in chromatin state and transcript levels of the cereal VERNALIZATION1 gene. J Exp Bot. 2013;64:2413-22.

37. Trevaskis B, Hemming MN, Dennis ES, Peacock WJ. The molecular basis of vernalization induced flowering in cereals. Trends Plant Sci. 2007;12:352-7.

38. Shcherban AB, Khlestkina EK, Efremova TT, Salina EA: The effect of two differentially expressed wheat VRN-B1 alleles on the heading time is associated with structural variation in the first intron. Genetica 2013, 141:133-141.

39. Xiao J, Xu S, Li C, XU Y, et al. O-GICNAc-mediated interaction between VER2 and TaGRP2 elicits TaVRN1 mRNA accumulation during vernalization in winter wheat. Nat Commun. 2014;5:4572.

40. Kippes N, Debernardia JM, Vasquez-Grossa HA, Akpinarb BA, et al. Identification of the VERNALIZATION 4 gene reveals the origin of spring growth habit in ancient wheats from South Asia. Proc Natl Acad Sci U S A. 2015;112(39):E5401-10.

41. Loukoianov A, Yan L, Blechi A, Sanchez A, Dubcovsky J. Regulation of VRN-1 vernalization genes in normal and transgenic polyploid wheat. Plant Physiol. 2005;138:2364-73

42. Díaz A, Zikhali M, Turner AS, Isaac P, Laurie DA. Copy number variation affecting the Photoperiod-B1 and Vernalization-A1 genes is associated with altered flowering time in wheat (Triticum aestivum). PLoS One. 2012;7(3):e33234.

43. Würschum $\mathrm{T}$, Boeven $\mathrm{PH}$, Langer $\mathrm{SM}$, Longin $\mathrm{C}$, Leiser W. Multiply to conquer: copy number variations at $P p d-B 1$ and $V r n-A 1$ facilitate global adaptation in wheat. BMC Genet. 2015;16:96.

44. Goncharov NP. Comparative genetics of wheats and their related species. Novosibirsk: Siberian University Press (In Russian). 2002. p. 251.

45. Kushnir U, Halloran GM. Variation in vernalization and photoperiod responses in tetraploid wheat (Triticum turgidum dicoccoides) ecotypes. J Appl Ecol. 1982;19:545-54.

46. Flood RG, Halloran GM. Genetics and physiology of vernalization response in wheat. Adv Agric. 1986;39:87-125.

47. Kato K, Mori Y, Beiles A, Nevo E. Geographical variation in heading traits in wild emmer wheat, Triticum dicoccoides. I. Variation in vernalization response and ecological differentiation. Theor Appl Genet. 1997;95:546-52.

48. Yan L, Loukoianov A, Blechl A, Tranquilli G, et al. The wheat VRN2 gene is a flowering repressor down-regulated by vernalization. Science. 2004b;303:1640-4.

49. Shcherban $A B$, Schichkina AA, Salina EA. The occurrence of spring forms in tetraploid Timopheevi wheat is associated with variation in the first intron of the VRN-A1 gene. BMC Plant Biol. 2016b;16(Suppl 3):236.

50. Takumi S, Koyama K, Fujiwara K, Kobayashi F. Identification of a large deletion in the first intron of the Vrn-D1 locus, associated with loss of vernalization requirement in wild wheat progenitor Aegilops tauschii Coss. Genes Genet Syst. 2011;86(3):183-95.

51. Hopf M, Zohary D. Domestication of plants in the old world: the origin and spread of cultivated plants in West Asia, Europe, and the Nile Valley. 3rd ed. Oxford [Oxfordshire]: Oxford University Press; 2000. p. 38. ISBN 0-19-850356-3

52. Ivanicova Z, Jakobson I, Reis $D$, Safar J, et al. Characterization of new allele influencing flowering time in bread wheat introgressed from Triticum militinae. N Biotechnol. 2016;33(5):718-27.

53. Chu CG, Tan CT, Yu GT, Zhong S, et al. A novel retrotransposon inserted in the dominant $\mathrm{V} r n-B 1$ allele confers spring growth habit in tetraploid wheat (Triticum turgidum L.). G3 (Bethesda). 2011;1(7):637-45.

54. Oliveira HR, Campana MG, Jones H, Hunt HV, et al. Tetraploid wheat landraces in the Mediterranean Basin: taxonomy, Evolution and Genetic Diversity. PLoS One. 2012;7(5):e37063.

55. Shcherban AB, Efremova TT, Salina EA. Identification of a new Vrn-B1 allele using two near-isogenic wheat lines with difference in heading time. Mol Breed. 2011;29(3):675-85. 
56. Muterko A, Kalendar R, Salina E. Allelic variation at the VERNALIZATION-A1, VRN-B1, VRN-B3 and PHOTOPERIOD-A1 genes in cultivars of Triticum durum Desf. Planta. 2016;244:1253-63.

57. Santra DK, Santra M, Allan RE, Campbell KG, et al. Genetic and molecular characterization of vernalization genes $V r n-A 1, V r n-B 1$ and $V r n-D 1$ in spring wheat germplasm from the Pacific northwest region of the USA. Plant Breed. 2009;128:576-84.

58. Milec Z, Sumikova T, Tomkova L, Pankova K. Distribution of different Vrn-B1 alleles in hexaploid spring wheat germplasm. Euphytica. 2013;192:371-8.

59. Shcherban AB, Borner A, Salina EA. Effect of VRN-1 and PPD-D1 genes on heading time in European bread wheat cultivars. Plant Breed. 2015a;34:49-55.

60. Iwaki K, Haruna S, Niwa T, Kato K. Adaptation and ecological differentiation in wheat with special reference to geographical variation of growth habit and Vrn genotypes. Plant Breed. 2001;120:107-14.

61. Zhang XK, Xiao YG, Zhang $Y, X i a X C$, et al. Allelic variation at the vernalization genes Vrn-A1, Vrn-B1, Vrn-D1, and Vrn-B3 in Chinese wheat cultivars and their association with growth habit. Crop Sci. 2008:48:458-70.

62. Eagles HA, Cane K, Kuchel H, Hollamby GJ, et al. Photoperiod and vernalization gene effects in southern Australian wheat crop pasture. Science. 2010;61:721-30.

63. Zhang J, Wang Y, Wu S, Yang J, et al. A single nucleotide polymorphism at the $V r n-D 1$ promoter region in common wheat is associated with vernalization response. Theor Appl Genet. 2012;125(8):1697-704.

64. Zhang X, Gao M, Wang S, Chen F, et al. Allelic variation at the vernalization and photoperiod sensitivity loci in Chinese winter wheat cultivars (Triticum aestivum L.). Front Plant Sci. 2015;6:470.

65. Muterko A, Balashova I, Cockram J, Kalendar R, et al. The new wheat vernalization response allele Vrn-D1s is caused by DNA transposon insertion in the first intron. Plant Mol Biol Rep. 2015;33(2):294-303.

\section{Submit your next manuscript to BioMed Central and we will help you at every step:}

- We accept pre-submission inquiries

- Our selector tool helps you to find the most relevant journal

- We provide round the clock customer support

- Convenient online submission

- Thorough peer review

- Inclusion in PubMed and all major indexing services

- Maximum visibility for your research

Submit your manuscript at www.biomedcentral.com/submit 